\title{
Componentes Fenólicos e Enzimas Oxidativas em Clones de Theobroma cacao Resistentes e Suscetíveis a Crinipellis perniciosa
}

\author{
Gutemberg Barone A. Nojosa*1, Mário Lúcio V. Resende' ${ }^{1}$, Marco Antônio G. Aguilar², \\ Kátia Maria T. Bezerra ${ }^{2}$ \& Dário E. Anhert ${ }^{3}$
}

${ }^{1}$ Departamento de Fitopatologia, Universidade Federal de Lavras, Cx. Postal 37, CEP 37.200-000, Lavras, MG, e-mail: bergne@ navinet.com.br; ${ }^{2}$ Centro de Pesquisa do cacau-CEPEC/CEPLAC, Cx. Postal 07, CEP 45.600-000, Itabuna, BA;

${ }^{3}$ Universidade Estadual de Santa Cruz, Ilhéus, Bahia

(Aceito para publicação em 25/11/2002)

Autor para correspondência: Gutemberg Barone de Araújo Nojosa

NOJOSA, G.B.A., RESENDE, M.L.V., AGUILAR, M.A.G., BEZERRA, K.M.T. \& ANHERT, D.E. Componentes fenólicos e enzimas oxidativas em clones de Theobroma cacao resistentes e suscetíveis a Crinipellis perniciosa. Fitopatologia Brasileira 28:148-154. 2003.

\section{RESUMO}

Os níveis de fenóis solúveis totais e a atividade das enzimas oxidativas polifenoloxidases e peroxidases foram estudados em tecidos foliares sadios dos clones de cacaueiro (Theobroma cacao) SCA 6, TSH 1188, TSH 565, TSH 516, EET 397, EET 62, TSA 641, SIAL 505, RIM 106, RIM 52, SIC 24 e UF 613, com o objetivo de estudar possível(is) mecanismo(s) de resistência de cacaueiro a Crinipellis perniciosa. Os níveis de fenóis solúveis totais foram mais elevados em clones de cacaueiro com resistência a $C$. perniciosa, e podem estar contribuindo na resposta de defesa contra o patógeno. A atividade de polifenoloxidases foi menor nos clones resistentes do que nos clones suscetíveis. A atividade de peroxidases em folhas maduras foi menor nos clones resistentes, mas em folhas jovens não foi possível estabelecer uma relação da atividade de peroxidase com os clones resistentes. Os níveis de fenóis e a atividade das enzimas oxidativas correlacionaram-se de forma inversa na maioria dos clones estudados, o que pode indicar uma inibição das enzimas peroxidases e polifenoloxidases pelos compostos fenólicos.

Palavras-chave adicionais: peroxidases, polifenoloxidases, vassoura-de-bruxa, cacau, resistência.

\begin{abstract}
Phenols and oxidative enzymes in resistant and susceptible cocoa clones against Crinipellis perniciosa

The levels of total soluble phenols and the activity of the oxidative enzymes polyphenol oxidases and peroxidases were studied in healthy leaf tissue of cocoa (Theobroma cacao) clones SCA 6, TSH 1188, TSH 565, TSH 516, EET 397, EET 62, TSA 641, SIAL 505, RIM 106, RIM 52, SIC 24 and UF 613, for the purpose of detecting the possible resistance mechanism(s) to Crinipellis perniciosa. The total soluble phenol content of T. cacao clones with resistance to $C$. perniciosa was generally higher than in

the susceptible clones, which may contribute to defense against the pathogen. The activity of polyphenol oxidases was lower in the resistant clones compared to the susceptible ones. The activity of peroxidases in mature leaves was lower in resistant clones, but when considering young leaves it was not possible to establish a clear relation between the activity of this enzyme with resistance. The levels of soluble phenols and the activity of oxidative enzymes studied were inversely correlated in the majority of the studied clones, suggesting a possible inhibition of the oxidative enzymes by phenols.
\end{abstract}

\section{INTRODUÇÃO}

Os mecanismos bioquímicos e fisiológicos de resistência do cacaueiro (Theobroma cacao L.) às principais doenças fúngicas são praticamente desconhecidos. Quando se tenta relacionar esses mecanismos com a doença vassoura-de-bruxa, causada por Crinipellis perniciosa (Stahel) Singer, os trabalhos relatados na literatura são extremamente escassos. Dentre alguns dos mecanismos bioquímicos de resistência às doenças estudados em cacau, destacam-se aqueles com participação de compostos fenólicos. Os primeiros trabalhos da área, ainda na década de 1960, destinaram-se a selecionar compostos

\footnotetext{
*Parte da Dissertação de Mestrado do primeiro autor. Universidade de Brasília. (1999)
}

fenólicos constitutivos possivelmente relacionados com a resistência de cultivares de cacau à Ceratocystis fimbriata Ellis et Halsted (Capriles de Reys et al., 1964; Capriles de Reys \& Reys, 1968). Capriles de Reys et al. (1964) encontraram na cultivar resistente IMC-67 um teor mais elevado de fenóis que na suscetível OC-61. Contudo, apesar do nível de ácido clorogênico em 'IMC-67' ser duas vezes maior que em 'OC-61', as concentrações em plantas resistentes sempre estiveram abaixo dos níveis requeridos para toxicidade in vitro. Capriles de Reys \& Reys (1968) encontraram outros compostos fenólicos em maior nível em 'IMC-67' e entre estes, um éster do ácido gentísico foi detectado em níveis fungitóxicos para $C$. fimbriata, no caule. A resistência do cacaueiro à murcha-de-Verticillium também foi estudada, como parte 
do sistema de resistência induzida, e quatro compostos pósinfeccionais do tipo fitoalexinas foram pela primeira vez isolados de cacaueiro, sendo um triterpenóide, dois compostos fenólicos e um composto rico em enxofre elementar (Resende et al., 1996).

Existem evidências de que fitoalexinas também estejam envolvidas na resistência de Theobroma spp. a Phytophthora spp. e a Crinipellis spp. Daguenet \& Parvais (1991) relataram a presença de uma substância com fluorescência azul escura, a qual provavelmente conferiria resistência de Theobroma grandiflorum (Spr.) K. Schum à Phytophthora palmivora (Butl.) Butl. após inoculação. Frias (1991) demonstrou, em cacaueiro, o desenvolvimento de uma fluorescência dourada nas células ao redor de estômatos invadidos por Crinipellis spp., que inibia a colonização dos tecidos adjacentes.

Os primeiros trabalhos tentando elucidar a natureza bioquímica e fisiológica dos distúrbios causados por $C$. perniciosa foram realizados na década de 1960 (Krupasagar, 1968; Krupasagar \& Sequeira, 1969) e os esforços foram concentrados no patógeno, tentando identificar as substâncias produzidas, que seriam responsáveis pelos desequilíbrios hormonais apresentados pelo cacaueiro. Krupasagar \& Sequeira (1969) identificaram duas oxidases, uma IAA-oxidase e uma lacase, ambas com capacidade de oxidar IAA e outros compostos fenólicos. De 1969 até agora, esse foi o único estudo contundente a respeito da ação do fungo na fisiologia do hospedeiro, enquanto que os estudos a respeito dos mecanismos de resistência bioquímica e fisiológica existentes no cacaueiro carecem de estudos mais aprofundados.

A atividade de enzimas oxidativas como peroxidases e polifenoloxidases têm sido bastante estudadas em plantas como parte dos mecanismos de defesas induzidas, ou em condições de estresse (Siegel, 1993; Sánchez et al.,2000), contudo a participação destas enzimas na resistência constitutiva, antes de ocorrer algum tipo de estresse, tem sido pouco estudada. Polifenoloxidases oxidam um amplo grupo de fenóis sem a necessidade de $\mathrm{H}_{2} \mathrm{O}_{2}$, contudo peroxidases catalisam reações de oxidação utilizando $\mathrm{o}_{2} \mathrm{O}_{2}$ como aceptor de elétrons, e atuam em vários processos metabólicos como: biossíntese de etileno, descarboxilação do ácido indol acético, lignificação da parede celular e respostas de estresse em geral (Siegel, 1993). No caso das polifenoloxidases, a atividade pode ser acrescida ou inibida em algumas plantas por estresses como injúrias, "chilling", toxicidade de nitrogênio e ataque de patógenos (Vaughn \& Duke, 1984; Sánchez et al., 2000).

O objetivo deste trabalho foi estudar os aspectos fisiológicos da participação de fenóis solúveis totais, polifenoloxidases e peroxidases no(s) mecanismo(s) de resistência constitutiva de tecidos foliares de clones de cacaueiro com diferentes níveis de resistência à $C$. perniciosa.

\section{MATERIAIS E MÉTODOS}

\section{Material vegetal e coleta de amostras}

Foram utilizados 12 clones de cacau com diferentes níveis de resistência a vassoura-de-bruxa (Tabela 1). Os clones foram mantidos em condições de campo, no banco ativo de germoplasma-BAG, do Centro de Pesquisas do Cacau CEPEC/CEPLAC, Ilhéus, BA. Folhas sadias em dois estágios de maturação: folhas jovens (folhas tenras, de cor vermelho arroxeado, e de cor verde claro no caso dos clones sem pigmentos) e folhas maduras (folhas coriáceas, de coloração verde-escuro) foram coletadas de plantas adultas, transportadas em isopor com gelo, e armazenadas em congelador a $-20{ }^{\circ} \mathrm{C}$ até se proceder as análises para a determinação do teor de fenóis solúveis totais, atividade de peroxidases (EC 1.11.1.7) e polifenoloxidases (EC 1. 10. 3.1; EC 1.10.3.2; EC 1.14.18.1). O material utilizado foi coletado em setembro de 1998, sempre entre 9:00 e 10:00 h da manhã.

\section{Delineamento experimental}

O número de árvores utilizadas no experimento para gerar as médias de cada clone variou de três a cinco. Duas amostras independentes de tecido sadio foram coletadas para cada uma destas plantas, sendo cada amostra constituída por duas sub-amostras coletadas em ramos diferentes da copa de cada árvore. Os clones encontravam-se completamente casualizados na área do BAG. As análises estatísticas foram realizadas em esquema fatorial, utilizando os 12 clones como um fator e os dois tipos de tecidos foliares (jovem e maduro) como um segundo fator $(12 \times 2)$ através do programa de análises estatistísticas ESTAT (Sistema para analises estatísticas v. 2.0) do Departamento de Ciências Exatas da UNESPFCAV, de Jaboticabal, SP.

\section{Extração e quantificação dos níveis de fenóis solúveis totais}

Amostras dos tecidos acondicionados em congelador $\left(-20{ }^{\circ} \mathrm{C}\right)$ foram macerados em almofariz com nitrogênio líquido. Foram retiradas $100 \mathrm{mg}$ de cada amostra macerada e misturadas com uma solução extratora $(1: 40$ p/v), constituída de metanol, clorofórmio e água desmineralizada (MCA, 12:5:3 v/v) para obtenção de um extrato bruto (EB). A extração foi realizada de acordo com a metodologia e condições descritas por Resende et al. (2000). Ao EB foram adicionados $1 \mathrm{ml}$ de clorofórmio e 1,5 $\mathrm{ml}$ de água desmineralizada; essa mistura foi agitada e centrifugada (10.000 $x \mathrm{~g}$ por $30 \mathrm{~min}$ a 4 ${ }^{\circ} \mathrm{C}$ ), para se realizar a separação de fases do EB (Bielesk \& Turner, 1966). Uma alíquota de $500 \mu \mathrm{l}$ da fase superior foi retirada para se determinar a concentração de fenóis solúveis totais. A quantificação de fenóis foi realizada com base em uma curva padrão de tirosina, conforme metodologia de Jennings (1981).

\section{Extração e mensuração da atividade de enzimas oxidativas}

O mesmo material armazenado utilizado para a determinação dos teores de fenóis solúveis totais foi utilizado para a determinação da atividade das enzimas peroxidases e polifenoloxidases.

A extração das enzimas foi realizada com tampão fosfato de potássio $0,1 \mathrm{M}, \mathrm{pH}$ 6,8, contendo EDTA $0,1 \mathrm{mM}$ (PBK). As amostras foram maceradas em almofariz com nitrogênio líquido e o tampão PBK foi homogeneizado (1:50 
$\mathrm{p} / \mathrm{v}$ ), após isso a suspensão obtida foi centrifugada para a obtenção de um extrato enzimático conforme descrito por Resende et al. (2000).

Atividade das Peroxidases (POs, EC 1.11.1.7) e polifenoloxidases (PPOs, EC 1.10.3.1; EC 1.10.3.2 e EC 1.14.18.1)

A determinação da atividade das POs nos tecidos foliares foi realizada de acordo com o método de Kar \& Mishra (1976), modificado. Alíquotas de $100 \mu \mathrm{l}$ do extrato enzimático foram adicionadas a 4,9 $\mathrm{ml}$ do meio de reação contendo tampão fosfato de potássio $25 \mathrm{mM} \mathrm{pH} \mathrm{6,8,} \mathrm{pirogalol} 20 \mathrm{mM}$ e $\mathrm{H}_{2} \mathrm{O}_{2} 20 \mathrm{mM}$ para POs e na ausência de $\mathrm{H}_{2} \mathrm{O}_{2}$ para PPOs. As amostras foram comparadas com uma solução controle, constituída do mesmo meio de reação, mais $100 \mu$ de tampão de extração, e $500 \mu 1$ de $\mathrm{H}_{2} \mathrm{SO}_{4}$ a $5 \%$ (v/v). A absorbância da reação foi determinada a $420 \mathrm{~nm}$, sendo acompanhada a cada 5 s durante $1 \mathrm{~min}$ a $28{ }^{\circ} \mathrm{C}( \pm 0.5)$ e a quantidade de purpurogalina formada foi medida, utilizando-se para os cálculos, o coeficiente de extinção molar de $2,47 \mathrm{mM}^{-1} \mathrm{~cm}^{-1}$ (Chance \& Maehley, 1955).

\section{RESULTADOS E DISCUSSÃO}

\section{Níveis de fenóis solúveis totais}

De acordo com os resultados (Figura 1), quando se considerou os níveis totais de fenóis nos genótipos, o clone SCA 6, considerado padrão de resistência a vassoura-de-bruxa, não apresenta diferenças significativas (Tukey 5\%) com os clones TSH 1188, TSH 565, TSH 516, SIAL 505, e EET 397 , contudo diferiu dos clones EET 62, SIC 24, RIM 52, UF 613, TSA 641, e RIM 106. Entre os clones que não apresentaram diferenças com SCA 6, apenas o clone SIAL-505 foi considerado como suscetível à $C$. perniciosa, contudo, em avaliações de incidência da vassoura-de-bruxa feitas pelo programa de melhoramento do CEPEC/CEPLAC, os clones da série SIAL apresentaram um nível de resistência na parte reprodutiva que permitiu seu agrupamento com o clone SCA 6 e com outros clones das séries do alto Amazonas, Peru e seus descendentes (Pires et al., 1999a). Além de um bom nível de resistência nos tecidos reprodutivos, outros fatores podem estar relacionados com a quantidade elevada de fenóis em tecidos do clone SIAL 505, como a pigmentação, aspecto importante, observado em muitos clones resistentes descendentes de SCA 6, enquanto que a cultivar Catongo albino é um reconhecido padrão de resistência.

Os clones que apresentaram os teores mais baixos de fenóis foram: SIC-24, EET 62, RIM 52, UF 613, TSA 641, e RIM 106 (Figura 1). Os clones da série EET e TSA têm descendência de SCA 6, porém, no caso dos clones EET 62 e TSA 641 o nível de resistência à $C$. perniciosa não possibilitou agrupá-los com os clones descendentes de SCA 6 que apresentavam baixo nível de doença (Pires et al., 1999a).

Os valores altos de fenóis encontrados nos clones resistentes representam um aspecto importante porque sugerem o envolvimento de compostos fenólicos na resistência constitutiva de cacaueiro contra $C$. perniciosa. Esse aspecto é reforçado com a observação de uma maior quantidade de fenóis em tecidos infetados em relação a tecidos sadios (Nojosa, 1999). Esse envolvimento de fenóis também já foi observado na resistência de cacaueiro contra outros patógenos como C. fimbriata (Capriles de Reys et al., 1964; Capriles de Reys \& Reys, 1968). Também é bastante interessante o fato do clone SIAL 505, que faz parte de uma série de clones suscetíveis, apresentar um nível de resistência, em tecidos reprodutivos, próximo ao encontrado em clones como SCA 6 e, ao mesmo tempo, apresentar altos valores de fenóis solúveis, também semelhantes ao SCA 6 (Figura 1). Por outro lado, os clones EET 62 e TSA 641, que fazem parte das séries de clones descendentes de SCA 6, mas que são suscetíveis, apresentaram valores muito baixo de fenóis solúveis semelhante ao dos clones suscetíveis UF 613, RIM 52, RIM 106 e SIC 24 (Figura 1). Os altos níveis de fenóis encontrados no clone SIAL 505 poderiam não ter nenhuma correlação com a resistência e, talvez, possam apenas estar relacionados com os níveis de antocianinas ou de outros compostos pigmentares deste clone. Contudo, acredita-se que esse não seja o caso, já que todos os clones resistentes ou com algum tipo de resistência (Tabela 1) apresentaram valores de fenóis

TABELA 1 - Origem e classificação quanto à resistência a Crinipellis perniciosa dos 12 clones de cacau (Theobroma cacao) avaliados

\begin{tabular}{|c|c|c|c|}
\hline Genótipo & Origem & $\begin{array}{c}\text { Resposta a } \\
\text { C. perniciosa }\end{array}$ & Referência \\
\hline TSH 1188 & Descendente de SCA 6 & $\mathrm{R}$ & Pires et al., 1999b \\
\hline TSH 565 & Descendente de SCA 6 & $\mathrm{R}$ & Pires et al., 1999b \\
\hline SIAL 505 & Bahia / Brasil & $\mathrm{RVA}^{\mathrm{a}} ; \mathrm{AS}^{\mathrm{b}}$ & ${ }^{\mathrm{a}}$ Pires et al., 1999b; a Luz, et al., 2001; ' ${ }^{\mathrm{b}}$ Reyes, 1996 \\
\hline SCA 6 & Peru & $\mathrm{R}^{\mathrm{a}}, \mathrm{AR}^{\mathrm{c}}$ & ${ }^{\mathrm{a}}$ Luz, et al., 2001; ${ }^{\mathrm{a}}$ Pires et al., 1999b; ' ${ }^{\mathrm{c}}$ Laker \& Sreenivasan, 1987 \\
\hline TSH 516 & Descendente de SCA 6 & $\mathrm{R}$ & Pires et al., 1999b \\
\hline EET 397 & Descendente de SCA 6 & $\mathrm{R}$ & Pires et al., 1999b; Luz, et al., 2001 \\
\hline SIC 24 & Bahia / Brasil & $\mathrm{AS}^{\mathrm{d}}, \mathrm{S}^{\mathrm{e}}, \mathrm{RVA}^{\mathrm{a}}$ & ${ }^{\mathrm{d}}$ Reyes, 1996; 'Silva et al., 1998; ${ }^{2}$ Pires et al., 1999b \\
\hline EET 62 & Los Rios / Equador & SRC & Luz, et al., 2001 \\
\hline RIM 52 & México & $\mathrm{S}$ & Pires et al., $1999 \mathrm{~b}$ \\
\hline UF 613 & Limon / Costa Rica & AS & Reyes, 1996 \\
\hline TSA 641 & Descendente de SCA 6 & $\mathrm{~S}$ & Pires et al., 1999b \\
\hline RIM 106 & México & $\mathrm{S}$ & Pires et al. 1999b \\
\hline
\end{tabular}

$\mathrm{S}=$ Suscetível, $\mathrm{R}=$ Resistente, $\mathrm{AR}=$ Altamente resistente, $\mathrm{AS}=$ Altamente suscetível, $\mathrm{SRC}=$ Resistente no campo e suscetível in vitro (inoculação artificial em mudas); RVA=Resistência a infecção em Almofada floral 
Componentes fenólicos e enzimas oxidativas em clones de Theobroma cacao...

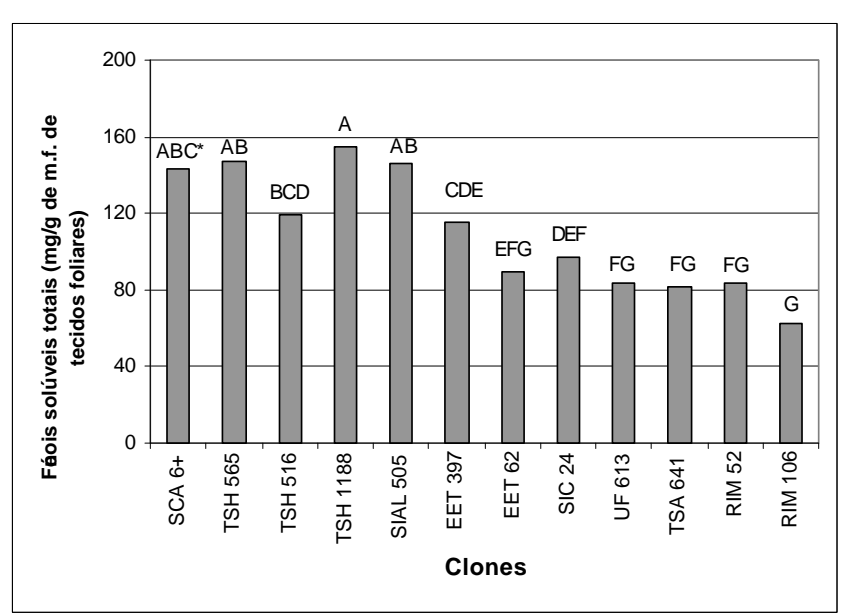

FIG. 1 - Médias de fenóis solúveis totais em tecidos foliares de 12 clones de cacau (Theobroma cacao). *Médias seguidas pelas mesmas letras não diferem entre si pelo teste de Tukey ao nível de $5 \%$.

significativamente diferentes daqueles clones comprovadamente suscetíveis, alguns também pigmentado, embora de forma menos intensa.

O clone TSA 641, oriundo do cruzamento de SCA 6 e IMC 67, deveria apresentar pelo menos parte do teor de fenóis encontrado no parental SCA 6, e um nível de resistência semelhante aos descendentes de SCA 6. Contudo, tanto a resistência como os níveis de fenóis que podem ser fatores correlacionados, neste clone podem ter sido herdados do parental IMC 67 o que justificaria também o fato deste clone ser suscetível, enquanto outros clones da série TSA são resistentes (Pires et al., 1999b).

Os clones UF 613 e RIM 52, considerados em avaliações do CEPEC/CEPLAC como suscetíveis, embora não apresentem os mais baixos níveis de fenóis, estão muito próximo desses níveis e não diferem significativamente dos clones TSA 641 e RIM 106, os quais apresentaram os mais baixos teores médios de fenóis.

Quando se analisou separadamente o teor de fenóis em tecidos de folhas novas e maduras (Tabela 2), verificouse que em folhas maduras o teor de fenóis foi maior em SCA que nos outros clones, contudo não houve diferenças significativas (Tukey 5\%) com os clones TSH 565, TSH 1188 , TSH 516, EET 397, EET 62, os quais apresentaram, respectivamente, níveis decrescentes de compostos fenólicos. Os clones RIM 52, UF 613 e RIM 106 não diferiram entre si, apresentando os menores níveis de fenóis em folhas maduras para os clones analisados. O clone SIAL 505, que na análise dos níveis totais de fenóis não diferiu do clone SCA 6 , aqui apresentou valores intermediários de fenóis, não diferindo dos clones com teores mais elevados, com exceção de SCA 6 e TSH 565, e nem dos clones com teores mais baixos.

Em folhas jovens, os clones SIAL 505 e TSH 1188 apresentaram os maiores níveis de fenóis e não diferiram entre si, contudo SIAL 505 diferiu de todos os outros clones analisados. O clone SCA 6 , mais uma vez não apresentou
TABELA 2 - Médias de fenóis solúveis totais (mg/g de mF) em folhas sadias jovens e maduras de 12 genótipos de cacau (Theobroma cacao) com níveis diferentes de resistência à Crinipellis perniciosa

\begin{tabular}{|c|c|c|c|}
\hline \multirow{2}{*}{$\begin{array}{l}\text { Genótipo } \\
\text { TSH-1188 }\end{array}$} & $\begin{array}{l}\text { Média de fenóis em } \\
\text { Folhas maduras * }\end{array}$ & \multicolumn{2}{|c|}{$\begin{array}{l}\text { Média de fenóis em } \\
\text { Folhas jovens } * \nabla\end{array}$} \\
\hline & $130.98 \mathrm{ABCb}$ & 178.47 & $\overline{\mathrm{ABa}}$ \\
\hline TSH-565 & 132.76 Abb & 160.84 & $\mathrm{Ba}$ \\
\hline SIAL-505 & $90.73 \quad \mathrm{CDEFb}$ & 201.69 & Aa \\
\hline SCA-6+ & 146.59 Аа & 140.30 & $\mathrm{BCa}$ \\
\hline TSH-516 & $130.84 \mathrm{ABCa}$ & 108.41 & CDa \\
\hline EET-397 & $119.52 \mathrm{ABCDa}$ & 112.20 & $\mathrm{CDa}$ \\
\hline SIC-24 & 102.18 BCDEFa & 92.87 & DEa \\
\hline EET-62 & 114.70 ABCDEa & 63.74 & $\mathrm{~Eb}$ \\
\hline RIM-52 & 85.77 DEFa & 82.21 & DEa \\
\hline UF-613 & 74.60 & 93.37 & $\mathrm{DEa}$ \\
\hline TSA-641 & $\mathrm{BCDEa}$ & 58.48 & $\mathrm{~Eb}$ \\
\hline RIM-106 & 62.58 & 62.96 & $\mathrm{Ea}$ \\
\hline
\end{tabular}

*Médias seguidas por mesmas letras maiúsculas nas colunas e minúsculas nas linhas não diferem entre si pelo teste de Tukey ao nível de 5\%. O experimento apresentou um CV de $13,8711 \%$.

diferenças com os clones TSH 1188, TSH 565, TSH 516 e EET 397, contudo diferiu dos demais clones suscetíveis. Os clones SIC 24, EET 62, RIM 52, UF 613, TSA 641 e RIM 106, não diferiram entre si.

É importante observar que a infecção do cacaueiro por C. perniciosa só ocorre em tecidos jovens, e que todos os clones considerados suscetíveis apresentaram níveis de fenóis em folhas jovens inferiores aos clones resistentes (Tabela 2). Apesar de não ocorrerem alterações significativas nos níveis de fenóis em folhas maduras e em folhas jovens do clone SCA 6, esses teores foram maiores que os teores nos clones suscetíveis. Além disso, os clones TSH 1188, TSH 565, SIAL 505, EET 62 e TSA 641 foram os únicos a apresentar diferenças significativas nos níveis de fenóis entre folhas maduras e jovens, sendo que nos três primeiros, que são resistentes, os valores de fenóis foram mais elevados em folhas jovens que em folhas maduras, e nos dois últimos que são suscetíveis, foram maiores em folhas maduras que nas jovens. Embora não se possa estabelecer correlações diretas entre o nível de fenóis e a percentagem de doença nas plantas, parece claro que os fenóis fazem parte dos mecanismos de defesa de cacaueiro contra $C$. perniciosa, pois há diferenças significativas nos níveis de fenóis de clones resistentes e suscetíveis, tanto em tecidos foliares jovens como em tecidos foliares maduros. Em outros patossistemas, compostos fenólicos constitutivos têm sido confirmados como fatores de resistência a patógenos em função de seus efeitos tóxicos ou sua atuação como inibidores de enzimas hidrolíticas. Pode-se citar como exemplos clássicos o catecol e o ácido protocatecóico em cebola (Allium cepae L.), catequina, galocatequina e isoquercitina em algodão (Gossypium hirsutum L.), hordatinas em cevada (Hordeum vulgare L.), além de outros, que apresentam níveis mais elevados nos materiais resistentes que nos suscetíveis (Vidhyasekaran, 1988; Nicholson, 1992). No caso de T. cacao - C. perniciosa, Bastos (1987) encontrou 
que extratos de cacau e compostos fenólicos têm efeito inibitório sobre a germinação de basidiósporos de C. perniciosa. Brownlee et al. (1992) determinaram que taninos condensados têm propriedades fungitóxicas e são abundantes em lançamentos de cacau. A participação de compostos fenólicos na resistência constitutiva de cacaueiro contra $C$. perniciosa parece clara, contudo, não se pode afirmar ainda, qual seria a contribuição desses compostos ou até que ponto a resistência pode ser condicionada por esses compostos. Para tanto, seriam necessários estudos sobre a evolução temporal de compostos fenólicos em tecidos de cacau e a identificação dos compostos fenólicos mais relevantes para conferir resistência contra $C$. perniciosa.

\section{Atividade de polifenoloxidases (PPOs) nos tecidos dos clones de T. cacao}

As atividades totais de PPOs em folhas (Figura 2) demonstraram que há uma separação dos clones em grupos, sendo que SIC 24 foi o que apresentou maior atividade diferindo dos demais clones. Os clones RIM 52, UF 613, TSA 641, RIM-106 e SIAL-505 não diferiram entre si e apresentaram atividade maior que SCA 6, o qual apresentou atividade de PPO intermediária, diferindo de todos os clones analisados. Dentre os clones TSH 1188, TSH 516, TSH 565, EET 397 e EET 62, que apresentaram atividade de PPOs menores que SCA 6 e não diferiram entre si, apenas o clone EET 62 teve comportamento diferente em relação aos níveis totais de fenóis, que foram muito baixos (Figura 1).

Em tecidos de folhas maduras, a atividade de PPOs do clone SCA 6 não diferiu dos clones TSH 1188 e EET 62, que não foram diferentes de TSH 516, TSH 565 e EET 397. Com exceção do clone EET 62, as atividades de PPOs demonstraram um comportamento semelhante aos encontrados para níveis de fenóis em folhas maduras (Tabela 2). O clone RIM 106 apresentou a maior atividade de PPOs em folhas maduras, diferindo dos demais clones. Os clones SIAL 505, UF 613, SIC 24, TSA 641 e RIM 52 não diferiram entre si e apresentaram níveis de PPOs maiores que SCA 6.

Em folhas jovens, com relação à atividade de PPOs, o clone SCA 6, mais uma vez, apresentou comportamento intermediário, mas não diferiu dos clones SIAL 505 e TSH 516. Com exceção dos clones EET 62 e RIM 106, os outros com níveis diferenciados de suscetibilidade a $C$. perniciosa, apresentaram atividade de PPOs em folhas jovens maiores que os clones com níveis diferenciados de resistência (Tabela 3). Em todos os clones, a atividade de PPOs diminuiu em folhas jovens em relação às folhas maduras, com exceção dos clones RIM 52 e SIC 24. O clone RIM 52 não apresentou diferenças significativas, entre folhas maduras e jovens, na quantidade de fenóis e atividade de PPOs. O clone SIC 24 teve uma atividade de PPOs maior em folhas jovens que em folhas maduras (Tabela 3).

Atividade de peroxidases nos tecidos dos clones de $T$. cacao

Da mesma forma que com a atividade total de PPOs, o clone SCA 6 apresentou valores médios de atividade total

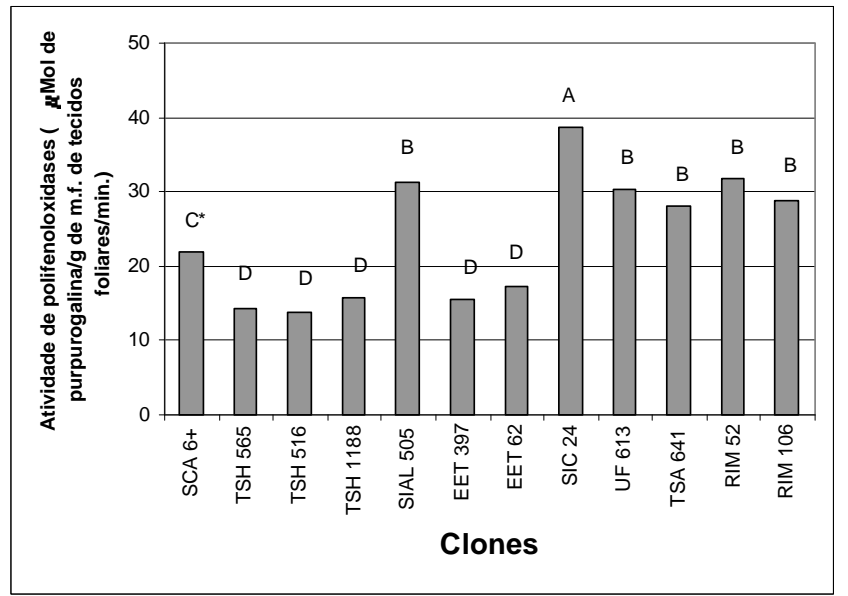

FIG. 2 - Médias da atividade de polifenoloxidases em tecidos foliares de 12 clones de cacau (Theobroma cacao). *Médias seguidas pelas mesmas letras não diferem entre si pelo teste de Tukey ao nível de $5 \%$.

de peroxidases intermediário entre os clones resistentes e suscetíveis, contudo não diferiu de RIM 106, TSA 641, EET 62 e TSH 1188 (Figura 3). O clone SIC 24, da mesma forma que com a atividade de PPOs, também teve os maiores valores totais de atividade de peroxidases, diferindo dos demais clones, e os valores mantiveram-se praticamente constantes em folhas jovens e maduras (Tabela 4). Os níveis de peroxidases em todos os outros clones foram menores em folhas jovens que em folhas maduras.

Em folhas maduras, o clone SCA 6 também apresentou valores intermediários de POs e não diferiu dos clones TSA 641, EET 62, TSH 1188 e EET 397. Embora em folhas maduras os níveis de peroxidase de SCA 6 , tenham sido mais próximos dos clones resistentes, em folhas jovens, eles foram

TABELA 3 - Médias da atividade de polifenoloxidases $(\mu \mathrm{Mol}$ de purpurogalina/g de $\mathrm{mF} / \mathrm{min}$ ) em folhas sadias jovens e maduras de 12 genótipos de cacau (Theobroma cacao) com níveis diferentes de resistência à Crinipellis perniciosa

\begin{tabular}{lrcrcc}
\hline \hline Genótipo & \multicolumn{2}{c}{$\begin{array}{c}\text { Médias da atividade } \\
\text { de polifenoloxidases } \\
\text { em Folhas maduras* }\end{array}$} & \multicolumn{3}{c}{$\begin{array}{c}\text { Médias da atividade } \\
\text { de polifenoloxidases } \\
\text { em Folhas jovens* }\end{array}$} \\
\hline SIC-24 & 36,5 & $\mathrm{BCb}$ & \multicolumn{2}{c}{40,8} & $\mathrm{Aa}$ \\
RIM-52 & 33,2 & $\mathrm{Ca}$ & 30,2 & $\mathrm{Ba}$ \\
UF-613 & 36,6 & $\mathrm{Bca}$ & 26,0 & $\mathrm{Bb}$ \\
TSA-641 & 35,5 & $\mathrm{Bca}$ & 25,1 & $\mathrm{Bb}$ \\
RIM-106 & $49,3 \mathrm{Aa}$ & 8,5 & $\mathrm{~Eb}$ \\
SIAL-505 & 40,5 & $\mathrm{Ba}$ & 15,6 & $\mathrm{CDb}$ \\
SCA-6+ & 26,4 & $\mathrm{Da}$ & 17,2 & $\mathrm{Cb}$ \\
EET-62 & 24,3 & $\mathrm{Dea}$ & 10,0 & $\mathrm{Deb}$ \\
TSH-1188 & 23,2 & $\mathrm{Dea}$ & 8,2 & $\mathrm{~Eb}$ \\
TSH-516 & 19,5 & $\mathrm{Ea}$ & 11,7 & $\mathrm{CDEb}$ \\
TSH-565 & 18,5 & $\mathrm{Ea}$ & 10,2 & $\mathrm{Deb}$ \\
EET-397 & 18,7 & $\mathrm{Ea}$ & 9,2 & $\mathrm{~Eb}$ \\
\hline
\end{tabular}

*Médias seguidas por mesmas letras maiúsculas nas colunas e minúsculas nas linhas não diferem entre si pelo teste de Tukey ao nível de 5\%. O experimento apresentou um CV de 11,3095\%. 
Componentes fenólicos e enzimas oxidativas em clones de Theobroma cacao...

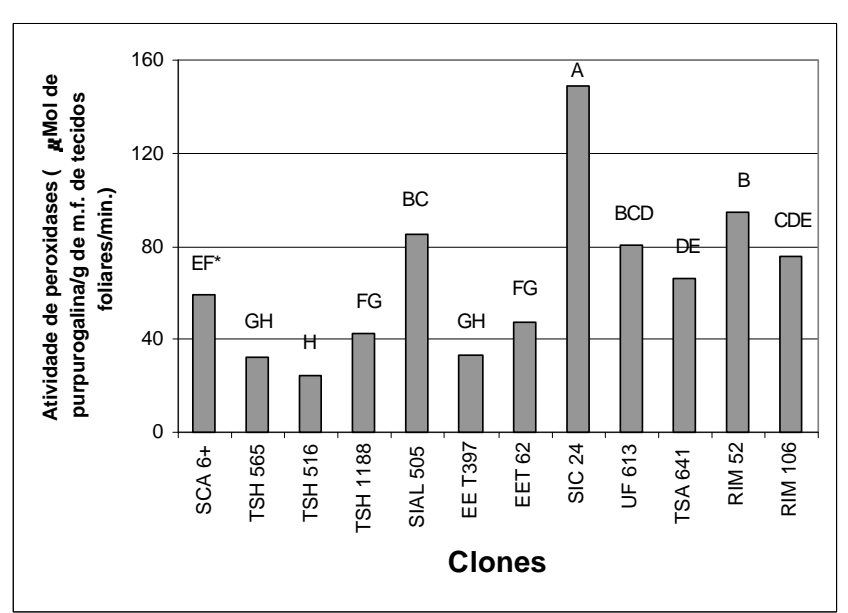

FIG. 3 - Médias da atividade de peroxidases em tecidos foliares de 12 clones de cacau (Theobroma cacao). *Médias seguidas pelas mesmas letras não diferem entre si pelo teste de Tukey ao nível de $5 \%$.

similares estatisticamente aos clones suscetíveis. Alta atividade de POs e isoenzimas de peroxidases têm sido relacionados à resistência, e algumas vezes utilizadas como marcadores bioquímicos de resistência em culturas como alface (Lactuca sativa L.) contra Bremia lactucae Regel, e melão (Cucumis melo L.) contra Pseudoperonospora cubensis (Berk. et Curtis) Rostowzew (Reuveni et al., 1991; Reuveni et al., 1992). Contudo, no caso de cacau, parece que o complexo de enzimas do tipo peroxidases avaliadas em sua atividade total não tem correlação com a resistência à $C$. perniciosa; mas é possível que existam isoenzimas do tipo peroxidase (Alcazar et al., 1995; Ndoumou et al. 1997) que atuem isoladamente no processo de defesa constitutiva, ou na defesa induzida em cacau (Resende et al., 2000). Algumas enzimas de peroxidases em Nicotiana sp. são determinadas por genes $\mathrm{S}$ de incompatibilidade, isso faria com que fossem encontradas variações dependentes das diferentes combinações dos alelos S (Pandey, 1967), o que poderia estar ocorrendo também em cacau, já que existem provavelmente cinco fatores de incompatibilidade com relações de dominância diferentes nas populações (Cope, 1962).

\section{Relação de fenóis solúveis totais e da atividade de enzimas PO e PPO em tecidos de clones de cacau}

A relação entre a atividade das enzimas oxidativas $\mathrm{PO}$ e PPO apresentou uma correlação negativa significativa com os níveis de fenóis em quase todos os clones estudados, sendo que o coeficiente de correlação dessas enzimas com os fenóis solúveis totais em folhas maduras foram: fenóis totais - POs $\mathrm{r}$ $=-0,815^{* *}$; fenóis totais - PPOs $\mathrm{r}=-0,873^{* *}$, POs - PPOs $\mathrm{r}=$ $0,902 * *$. Em folhas novas ocorreu uma correlação significativa apenas entre PO e PPO ( $\mathrm{r}=0,917 * *)$, e não ocorreu relação significativa entre PO e fenóis $(r=-0,259$ $n s)$ e PPO e fenóis ( $r=-0,309$ ns). Ao que parece, sob altas concentrações de compostos fenólicos, as enzimas que oxidam compostos fenólicos, como PO e PPO, são inibidas em folhas
TABELA 4 - Médias da atividade de peroxidases ( $\mu$ Mol de purpurogalina/g de $\mathrm{mF} / \mathrm{min}$ ) em folhas sadias jovens e maduras de 12 genótipos de cacau (Theobroma cacao) com níveis diferentes de resistência à Crinipellis perniciosa

\begin{tabular}{llllc}
\hline \hline Genótipo & $\begin{array}{c}\text { Médias da atividade } \\
\text { de peroxidases em } \\
\text { Folhas maduras * }\end{array}$ & \multicolumn{3}{c}{$\begin{array}{c}\text { Médias da atividade } \\
\text { de peroxidases em } \\
\text { Folhas jovens * }\end{array}$} \\
\hline SIC-24 & $147,6 \mathrm{Aa}$ & \multicolumn{2}{c}{150,8} & $\mathrm{Aa}$ \\
RIM-52 & $119,9 \mathrm{Ca}$ & 68,7 & $\mathrm{Bb}$ \\
SIAL-505 & $156,0 \mathrm{Aa}$ & 14,3 & $\mathrm{~Eb}$ \\
UF-613 & $122,4 \mathrm{Bca}$ & 38,7 & $\mathrm{CDb}$ \\
RIM-106 & $144,5 \mathrm{Aba}$ & 6,2 & $\mathrm{~Eb}$ \\
TSA-641 & 85,8 & $\mathrm{Da}$ & 47,2 & $\mathrm{BCb}$ \\
SCA-6+ & 71,4 & $\mathrm{Dea}$ & 46,8 & $\mathrm{BCb}$ \\
EET-62 & 77,3 & $\mathrm{Da}$ & 17,3 & $\mathrm{DE} b$ \\
TSH-1188 & 76,6 & $\mathrm{Da}$ & 8,9 & $\mathrm{~Eb}$ \\
EET-397 & 49,9 & $\mathrm{Efa}$ & 16,1 & $\mathrm{DEb}$ \\
TSH-565 & 42,6 & $\mathrm{Fa}$ & 22,3 & $\mathrm{DEb}$ \\
TSH-516 & 38,0 & $\mathrm{Fa}$ & 10,2 & $\mathrm{~Eb}$ \\
\hline
\end{tabular}

*Médias seguidas por mesmas letras maiúsculas nas colunas e minúsculas nas linhas não diferem entre si pelo teste de Tukey ao nível de 5\%. O experimento apresentou um CV de $15,7391 \%$.

maduras. O mesmo não ocorreu em folhas novas com os clones estudados. Uma inibição de PO e PPO por fenóis também já foi encontrada por Rivero et al. (2001) em plantas de tomateiro (Lycopersicon esculentum Mill) e melancia [Citrullus lanatus (Thumb.) Matsum \& Nakai], quando o alto nível de fenóis foi correlacionado com uma alta atividade de fenilalanina amônia-liase, enzima chave na rota de fenóis na maioria das dicotiledôneas. Em cacau, uma relação inversa também foi encontrada por Ndoumou et al. (1997) em tecidos de embriogênese somática, entre fenóis e enzimas oxidativas (peroxidase e IAA-oxidases), sendo que uma isoenzima de peroxidase ácida desapareceu dos tecidos com níveis altos de fenóis.

Embora estudos detalhados a respeito dos mecanismos bioquímicos envolvendo fenóis em cacau sejam necessários, é provável que fenóis e PPOs atuem como parte de um conjunto de fatores constitutivos para determinar os níveis diferentes de resistência dos clones aqui estudados.

\section{AGRADECIMENTOS}

Aos Setores de Fisiologia e Fitopatologia da CEPLACCEPEC (Comissão Executiva do Plano da Lavoura Cacaueira) pelos materiais vegetais, reagentes e equipamentos cedidos. À Dra. Edna Dora M. N. Luz pela valiosa contribuição nas sugestões.

À CAPES pela concessão de auxílio bolsa durante o desenvolvimento desse trabalho.

\section{REFERÊNCIAS BIBLIOGRÁFICAS}

BASTOS, C.N. Efeito inibitório de extratos de cultivares de cacau e compostos fenólicos sobre a germinação de basidiósporos de isolados de Crinipellis perniciosa. Proceedings of 10th International Cocoa Research Conference, 1987. Santo Domingo. 1987. 
pp.371-374.

BIELESK, R.L. \& TURNER, N.A. Separation and estimation of amino acids in crude plant extract by thin layer electrophoresis and chromatography. Analytical Biochemistry 17:278-293. 1966.

BROWNLEE, H.E., MCEUEN A.R., HEDGER J. \& SCOTT, I.M. Antifungal effects of cocoa tannin on the witches' broom pathogen Crinipellis perniciosa. Physiological and Molecular Plant Pathology 36:39-48. 1992.

CAPRILES DE REYS, L. \& REYS H.E. Contenido de polifenoles en dos variedades de Theobroma cacao L. y su relacion con la resistencia a Ceratocystis fimbriata. Agronomia Tropical 18:339-355. 1968.

CAPRILES DE REYS, L., SCHULZ, E.S. \& MUNOZ, A. El contenido de acido clorogenico con diferentes variedades de cacau y su relacion con la resistencia contra el hongo Ceratocystis fimbriata. Agronomia Tropical 16:273-284. 1964.

CHANCE, B. \& MAEHLEY, A.C. Assay of catalase and peroxidase. Methods in Enzymology 2:764-775. 1955.

COPE, F.W. The mechanism of pollen incompatibility in Theobroma cacao L. Heredity 17:157-182. 1962.

DAGUENET G. \& PARVAIS J.P. Etude comparative de la resistance a Phytophthora palmivora (Butl.) Butl. emend. Bras. et Grif. de trois especes du genre Theobroma. Mise en evidence de substances de type phytoalexins responsable de la resistance induite. Cafe Cacao The 25:181-190. 1991.

ESTAT - Programa de analises estatísticas. Sistema para analises estatísticas v. 2.0. Depto. de Ciências Exatas da UNESP-FCAV, Jaboticabal, SP. 1993.

FRIAS, G.A. Infection biology of Crinipellis perniciosa on vegetative flushes of cacao. Plant Disease 75:552-556. 1991.

JENNINGS, A.C. The determination of dyhydroxy phenolics compounds in extrats of plants tissues. Analytical Biochemstry 17:278-293. 1981.

KAR, M.E \& MISHRA, D. Catalase, peroxidase and polyphenoloxidase activities during rice leaf senescence. Plant Physiology 57:315-319. 1976.

KRUPASAGAR, V. \& SEQUEIRA, L. Auxin destruction by Marasmius perniciosus. American Journal of Botany 56:390-397. 1969.

KRUPASAGAR, V. Auxin destruction by Marasmius perniciosus. (M.S. Thesis). Madison. University of Wisconsin. 1968.

LUZ, E.D.M.N. Selection and generation of witches'broom resistant cacao genotypes at Itabuna, Bahia, Brasil. 2001.

NDOUMOU, D.O., NDZOMO, G.T. \& NIEMENAK, N. Phenol content, acidic peroxidase and IAA-oxidase during somatic embryogenesis in Theobroma cacao L. Biologia Plantarum 39:337347. 1997.

NICHOLSON, R.L. Phenolic compounds and their role in disease resistance. Annual Review of Phytopathology 30:369-389. 1992.

NOJOSA, G.B.A. Participação de fenóis e enzimas oxidativas nos mecanismos bioquímicos de resistência constitutiva e induzida do cacaueiro (Theobroma cacao L.) à Crinipellis perniciosa (Stahel) Singer. (Dissertação de Mestrado). Brasília. Universidade de Brasília. 1999.

PANDEY, K.K. Origin of genetic variability:combinations of peroxidase isoenzymes determine mutiple allelism of the $\mathrm{S}$ gene. Nature 213:669. 1967.

PIRES, J.L., MONTEIRO, W.R., LUZ, E.D.M.N., SILVA, S.D.V.M., PINTO, L.R.M., FIGUEIRA, A., GRAMACHO, K.P., LOPES, U.V., ALBUQUERQUE, P.S.B., YAMADA, M.M., AHNERT, D.E. \& BRUGNEROTTO, M.I.B. Cocoa breeding for witches' broom resistance at CEPEC, Bahia, Brazil. Proceedings of the International Workshop on the Contribuition on Disease Resistance to Cocoa Variety Improvement. INGENIC. 1999a. pp.91-101.

PIRES, J.L., MONTEIRO, W.R., PINTO, L.R.M \& LUZ, E.D.M.N. Resistance to witches' broom - evaluation of genotypes from different origins. Proceedings, 12, International Cocoa Research Conference, Cocoa Producers' Alliance, Lagos, 1999b. pp.389-397.

RESENDE, M.L.V., COOPER, R.M., FLOOD, J., ROWAN, M.G., BEALE, M.H., \& RAMSDEN, J.D. Involvement of condensed tannins and phytoalexins in the resistance of cocoa (Theobroma cacao L.) to Verticillium wilt. Physiological and Molecular Plant Pathology 48:347-359. 1996.

RESENDE, M.L.V., NOJOSA, G.B.A., AGUILAR, M.A.G., SILVA, L.H.C.P., NIELLA, G.R., CARVALHO, G.A., GIOVANINI, G.R. \& CASTRO, R.M. Perspectivas da indução de resistência em cacaueiro contra Crinipellis perniciosa através do benzotiadiazole (BTH). Fitopatologia Brasileira 25:149-156. 2000.

REUVENI, R., SHIMONI, M. \& CRUTE, I.R.. An association between high peroxidase activity in lettuce (Lactuca sativa) and field resistance to downy mildew (Bremia lactuca). Journal of Phytopathology 132:312-318. 1991.

REUVENI, R., SHIMONI, M., KARCHI, Z. \& KÚC, J. Peroxidase activity as a biochemical marker for resistance of muskmelon (Cucumis melo) to Pseudoperonospora cubensis. Phytopathology 82:749-753. 1992.

SÁNCHEZ, E., SOTO, J.M., GARCIA, P.C., LÓPEZ-LEFEBRE, L.R., RIVERO, R.M., RUIZ, J.M. \& ROMERO, L. Phenolic compounds and oxidative metabolism in green bean plants under nitrogen toxicity. Australian Journal of Plant Physiology 27:973978. 2000.

SIEGEL, B.Z. Plant peroxidases - an organismic perspective. Plant Growth Regulation 12:303-312. 1993.

SILVA, S.D.V.M., LUZ, E.D.M.N. \& MATSUOKA, K. Seleção de variáveis na avaliação de progênies de cacaueiro (Theobroma cacao) quanto à resistência a Crinipellis perniciosa. Agrotrópica 10:8794. 1998.

VAUGHN, K.C. \& DUKE, S.O. Function of polyphenol oxidase in higher plants. Physiologia Plantarum 60:106-112. 1984.

VIDHYASEKARAN, P. Phenolics in disease resistance. In: Vidhyasekaran, P. (Ed.) Physiology of Disease Resistance in Plants. Boca Raton, Florida. CRC Press. Inc. 1988. V.2. pp.49-81. 